\title{
El impacto de la industria petrolera en la economía mexicana.
}

\author{
Rafael A. Sánchez.
}

En el presente artículo se presenta un análisis sobre el desarrollo de la industria petrolera en México y sobre la importancia de ésta para el desarrollo económico de éste país. Consta de tres secciones en donde se analiza en primer lugar; el desarrollo de dicha industria desde sus inicios a finales del siglo pasado y hasta la década de 1970. En segundo lugar; se analiza la relación existente entre la industria del petróleo y la política exterior seguida por México, en donde el petróleo ha sido utilizado por los gobiernos de dicho país como un instrumento de la política exterior mediante el cual se ha buscado realizar objetivos nacionales en la politica internacional. Finalmente, en la uiltima sección se analiza el rol del petróleo en el forjamiento de la crisis económica que ha sufrido México desde 1980 y también, el rol de éste en el actual proceso de liberalización comercial y' de ajuste estructural de la economía.

\section{Introducción}

El petróleo constituye una mercancía cuyo valor sobrepasa el aspecto económico y ha sido también decisivo en los campos de la estrategia militar y política internacional. En la guerra, por ejemplo, durante la primera y segunda guerra mundial, las potencias beligerantes descubrieron que la utilización del petróleo representaba una ventaja militar comparativa que permitía reducir distancias e incrementar el daño asestado al enemigo. Así, el petróleo llegó a convertirse en un material decisivo para el desarrollo económico de los países. En 1973, los países miembros de la OPEP descubrieron que con la producción de petróleo bajo su control, podían modificar los términos de sus relaciones económicas con respecto al mundo 
desarrollado y así mejorar sus ingresos de exportación y su desarrollo económico. Igualmente, aprendieron que podían utilizar el petróleo como arma política contra el Estado de Israel y sus aliados (embargo petrolero contra Estados Unidos y Holanda en 1974 por su apoyo a Israel en la guerra contra el mundo Arabe). La guerra del Golfo Pérsico contra Irak en 1990, fue la última guerra que se peleó como consecuencia, inter alia, del valor estratégico del petróleo en la política mundial.

En este ensayo se analiza la importancia del petróleo para el desarrollo industrial y económico de México. En las tres secciones de que consta el ensayo se analiza de como los gobiernos mexicanos han utilizado el petróleo como pieza clave del desarrollo industrial del país, proveyendo internamente la utilización de energía barata. El petróleo también fue la base para el desarrollo de una política exterior activa orientada a abrir espacios en la política mundial donde México ha buscado jugar un rol de liderazgo en el Tercer Mundo, a la vez que, promover un mayor acercamiento de México con los países industrializados. El petróleo fue utilizado, en este sentido, para atraer inversiones masivas de capital que en el largo plazo degeneraron en una agobiante deuda externa que inclusive hoy condiciona el crecimiento económico de México y ha forzado a los gobiernos, desde 1983, a implementar ajustes económicos impopulares que han afectado la calidad de vida del pueblo mexicano. Se analiza, así, la crisis mexicana, sus efectos y el proceso de apertura de la economía que ha llevado a México abrir, no sólo el mercado en general, sino la industria del petróleo, en particular, a la inversión extranjera, especialmente norteamericana. El petróleo continúa siendo la base para la concertación de nuevos compromisos de deuda externa, sin los cuales la economía mexicana, según parece, no sería operable.

\section{El petróleo como motor del desarrollo ecónomico}

La industria petrolera en México estuvo hasta 1937, bajo el control monopólico de compañías multinacionales británicas y estadounidenses. La Royal Dutch-Shell y la Standard Oil de Nueva Jersey eran las empresas predominantes y sus inversiones también incluían actividades mineras y ferroviarias (Durán, 1985:PP.151-152). 
Anterior a la revolución, la dictadura de Porfirio Días (1876-1910) implementó una política económica liberal orientada a favorecer la inversión extranjera. La legislación de entonces sobre tenencia de la tierra, la cual garantizaba la propiedad absoluta del subsuelo al tenedor o propietario, motivó a las compañías petroleras a comprar o hacer largos contratos de arriendos, bajo el supuesto de que la ley les daba el derecho de explotar a perpetuidad los yacimientos minerales - incluyendo el petróleo, que se háyase en dichas propiedades (Ibid:P.157). Como consecuencia de dicha política liberal, las compañías petroleras realizaron inversiones masivas de capital en México, las cuales crecieron de $\$ 15$ millones en 1912 a $\$ 200$ millones en 1919 e inclusive $\$ 500$ millones en 1926.

La revolución no disuadió a las multinacionales de expandir sus inversiones en México. En la medida en que éstas depositaban su seguridad tanto en la protección diplomática que podrían recibir de sus gobiernos, así como en la debilidad y carencia de una clara definición ideológica de los gobiernos revolucionarios, el cambio político en el país no parecía poner en riesgos sus inversiones. Los gobiernos mexicanos, al inicio de la revolución, no sólo necesitaban los recursos provenientes de los impuestos y royalties pagados por las compañías extranjeras sino que, además, carecían de una conciencia transformista con respecto al futuro económico del país. La revolución básicamente consistió en derrocar al régimen de Porfirio Días cuyo programa de modernización económica excluyó a una vasta mayoría de la población, especialmente mestizos e indios, del bienestar, pero se careció de una conciencia revolucionaria en el sentido moderno del término. El proyecto político de Francisco Madero, por ejemplo, consistió básicamente en instaurar un régimen democrático-liberal basado en el sufragio efectivo y en la no reelección presidencial, sin haber mostrado una mayor preocupación por los aspectos económicos y, especialmente, el latente problema agrario creado por la reforma liberal porfirista (véase, Villegas, 1986:PP.101-2, 106).

Apoyadas en dicha percepción sobre la revolución, las compañías petroleras no sólo adoptaron una actitud despreocupada con respecto a la seguridad de sus inversiones, sino que hasta arrogante e inflexible en sus relaciones con los gobiernos posrevolucionarios. La inversión extranjera en el sector petrolero fue siempre creciente, lo que trajo como resultado el surgimiento de México durante la década de 1920 como uno de los mayores productores 
de petróleo a nivel mundial, el segundo exportador mundial de petróleo después de los Estados Unidos. La producción se incrementó de 2,552 barriles por día (b/d) en 1918 a un pico de 58,713 b/d en 1923 (Brown, 1985:P.24).

A pesar de que en los años iniciales los gobiernos revolucionarios no parecían proponerse a realizar una transformación del engranaje social y económico del país, desde 1915, el gobierno empezó a imponer controles sobre las actividades de las compañías petroleras. En ese año el presidente Venustiano Carranza creó una Comisión Técnica a la cual se le encargó la tarea de definir e implementar de la política petrolera que seguiría el país. Posteriormente, en 1917, se adoptó una nueva constitución política en la que se declaró la nacionalización del subsuelo mexicano. El presidente Carranza estaba determinado ha asegurar que la soberanía de México iba a ser respetada por las multinacionales y que éstas, en consecuencia, no usarían su influencia con sus gobiernos con el objeto de presionar a México para que aceptara una legislación que no le era conveniente (Philip, 1982:P.203).

Las compañías petroleras protestaron contra la nacionalización del subsuelo estipulado en el art. 27 de la constitución, argumentando que dicha medida no podía ser aplicada a concesiones hechas con anterioridad a la adopción de la nueva constitución, señalaban al efecto el principio de no retroactividad de la ley. Las concesiones que defendían habían sido otorgadas con base en el Código Minero de 1884, el cual quedaba abrogado (Bennett, et al, 1978:P.263). El art. 27 de la constitución, sin embargo, no era de aplicación inmediata y no fue sino hasta 1925 que el presidente Elías Calles lo hizo efectivo. El presidente Calles adoptó una política fiscal mucho más precisa en lo que atañe a las empresas petroleras, estableciendo, además, límites claros en cuanto a la duración de las concesiones hechas a dichas empresas. Así, estableció que dichas concesiones caducarían 50 años después de su adquisición y que, entonces, los activos pasarían a manos del Estado.

Las medidas adoptadas por el presidente Calles fueron el reflejo de un México más maduro en su proceso revolucionario y más claro en cuanto al futuro político y económico del país. Elías Calles introdujo y operacionalizó el partido único en la política mexicana como una forma efectiva de acabar con el faccionalismo y con los localismos que agobiaban al país en 
el período posrevolucionario. El partido único, entonces, fue concebido como una acción centralizadora del estado, la cual llevaría a México hacia un largo período de estabilidad político-institucional y hacia un mejor replanteamiento de su desarrollo económico.

Las compañías petroleras rechazaron dichos cambios en la legislación y expresaron que ellas no necesitaban obedecer la ley de México (Philip, Op.cit:P.205). Igualmente, dichas compañías trataron de sobornar al gobierno y a obligarlo a dar marcha atrás en sus posiciones nacionalistas, recurriendo para ello a una reducción de sus inversiones, lo cual produjo una caída de la producción petrolera; además, empezaron a trasladar parte de su estructura productiva hacia Venezuela donde los costos de producción eran más bajos y no había intervención gubernamental.

Para 1928, las compañías ya habían logrado forzar al gobierno a decretar incentivos con el fin de incrementar la producción y las exportaciones de petróleo (Durán, Op.cit:P.167). Sin embargo, la industria del petróleo se hallaba ya en una fase irreversible de decadencia y la posición internacional de México como productor y exportador mundial de petróleo había sido substancialmente deteriorada. A pesar de que en 1930 se encontraron nuevos depósitos (depósitos de Poza Rica), con lo que se produjo una ligera recuperación de la industria, la tendencia decadente de ésta no fue realmente conregida.

El cambio jurídico y político más destacante que se produjo en México con respecto al desarrollo de la industria petrolera tuvo lugar en el período 1934-39, cuando Lázaro Cárdenas arribó al poder. Cárdenas llegó al poder en un período en que el populismo latinoamericano se hallaba en un gran apogeo, precedido por Getulio Vargas en Brasil en 1930, y sucedido por Juan Domingo Perón en la Argentina en 1945. Este fue un período de gran relevancia en la política latinoamericana, en que líderes políticos carismáticos promovieron el control nacional de los recursos mineros y de sectores económicos considerados estratégicos para el desarrollo nacional, procurando, en consecuencia, alianzas con sectores progresistas afines a la idea del nacionalismo económico.

Cárdenas hizo una aplicación efectiva de los art. 27 y 123 de la constitución política. Este último referente a garantías laborales y sociales. Con Cárdenas, el proceso revolucionario entró en una fase de consolidación institucional y política. Con anterioridad a Cárdenas, la inestabilidad había sido la norma en la política mexicana y la posibilidad del golpe de Estado 
no estaba excluida, como lo experimentó Alvaro Obregón en 1923. En síntesis, Cárdenas trajo estabilidad al sistema político mexicano y le dio a la revolución el contenido social del que carecía, promoviendo los derechos laborales y la reforma agraria, lo cual le cosechó un amplio apoyo político, que, a la vez, le permitió crear las bases para la modernización económica y social del país, lo cual se haría tanto mediante la intervención del Estado en la forma de planificación económica, así como a través de la inserción de éste directamente en la actividad productiva.

En 1936, la industria del petróleo se hallaba en una profunda crisis. Los trabajadores demandaban de las compañías aumentos salariales y mejoras en las condiciones de trabajo. Como las compañías no aceptaron dichas demandas, las organizaciones laborales, las cuales se habían fortalecido como resultado de la política social del gobierno, iniciaron el 28 de mayo de 1937 una huelga general en las zonas petroleras. Una misión gubernamental determinó que las compañías deberían pagarle a los trabajadores alrededor de 26 millones de pesos. Las compañías rechazaron dicho reclamo sobre la base de que estaba más allá de sus posibilidades y, en cambio, ofrecieron pagar 14 millones ( $\$ 1.7$ millones), lo cual era inaceptable para los trabajadores. De acuerdo con una investigación gubernamental, las compañías tuvieron ingresos promedios anuales de 56.260 millones de pesos en el período 1934-936, contra 22.890 millones que ellas reconocían haber obtenido. Un representante de la Standard Oil de Nueva Jersey declaró que ellos no podían pagar y que no era su voluntad hacerlo, actitud que era basada en la creencia de que ellos podían amenazar al gobierno con la pérdida de ingresos en el erario público (Basurto, 1976:P.41).

Debido a las consecuencias políticas y socioeconómicas asociadas a la actitud negativa de las compañías con respecto a las demandas en cuestión, las que al parecer hicieron una lectura errónea del panorama político, el gobierno decidió el 18 de mayo de 1938, expropiar los bienes de las compañías, procediendo a su nacionalización o posesión pública como una medida preventiva. La nacionalización de la industria obedeció a razones que sobrepasan la mera confrontación laboral. Fue sobre todo, producto de un desarrollo de la conciencia nacional y de una mayor consolidación política-institucional del Estado mexicano.

Las compañías petroleras no sólo mal interpretaron la política interna de México sino también el ambiente externo caracterizado por la existencia 
de condiciones de pre-guerra internacional y por una nueva política estadounidense de cara a América Latina basada en la cooperación y en la solución pacífica de controversias (el buen vecino). Debido a dichas condiciones, el gobierno de Roosevelt decidió aceptar el acto de nacionalización emprendido por México siempre y cuando el gobierno mexicano pagara a las compañías una compensación adecuada como lo establecía la misma ley de nacionalización y se aceptó la expropiación como un derecho legal de México, sin pensarse en el uso de la fuerza, hazaña que veinte años antes se hubiese considerado como imposible (Eisenhower, 1962:P.41).

El 20 de julio de 1938, el gobierno de México creó la compañía estatal Petróleos Mexicanos (PEMIEX) como la entidad del Estado encargada de definir la política y manejo de la industria del petróleo. La producción. petrolera, ahora en manos del Estado, sería orientada a satisfacer las necesidades demandadas por el proceso de industrialización del país. La nacionalización de la industria fue una verdadera lección para las compañías extranjeras no sólo porque evidenció que un país en desarrollo podía retar su poder, sino que además, demostró que un país como México podía sacar adelante la industria del petróleo, a pesar de sus limitados recursos. Igualmente demostró que el apoyo diplomático de los Estados Unidos hacia las compañías petroleras no era ilimitado y que podía ser subordinado a intereses geopolíticos según lo dictara el imperativo de la seguridad nacional estadounidense.

El acto de nacionalización, sin embargo, no estuvo libre de consecuencias. En el corto plazo trajo como efecto represalias económicas y financieras (fuga de capital y retiro de financiamiento externo (Bannett et al, Op.cit:P.264). En el largo plazo implicó que México perdiera su posición prominente como exportador mundial de petróleo, posición que sólo sería recuperada en la década de 1970, cuando el país resurge como uno de los mayores exportadores de petróleo a nivel mundial.

Como se ha señalado, después de la nacionalización de la industria petrolera, México perdió su posición como mayor exportador mundial de petróleo y dedicó la producción de éste para apoyar la creciente demanda interna de energía de cara al proceso de industrialización que venía emprendiendo el país. El precio del petróleo y sus derivados para consumo local se mantuvo bajo con el fin de estimular la economía y el crecimiento económico. En palabras de Corredor Esnaola: 
"Lo que hace en realidad el pais es aprovechar una ventaja comparativa por dotación de factores, fundamentada en la magnitud de su potencial petrolero, en los costos muy bajos de extracción y en el hecho de que, por contar con una economía relativamente grande y diversificada, México tiene sectores estratégicos que son grandes consumidores de energía y pueden aprovechar dicha ventaja en la competencia internacional.»

(Corredor Esnaola, 1981: P.1313)

Sin embargo, en términos del uso racional de los factores económicos, poseer un recurso en abundancia no significa necesariamente que haya que gastarlo irracionalmente, aún cuando dicho uso se haga en nombre de la promoción del desarrollo nacional. Este parece ser el patrón seguido por México con respecto al uso de su petróleo. Mientras que el precio internacional del petróleo en septiembre de 1980 era de $\$ 32.7$ por barril, en México el precio para el consumo interno era de $\$ 7.8$ por barril, y esto va más allá de cualquier concepción equilibrada sobre el uso de los recursos económicos. A nuestro juicio este mal uso de un recurso tan valioso ha tenido tres importantes implicaciones para el desarrollo mexicano:

a) El uso indiscriminado del petróleo, basado en su abundancia, trajo como consecuencia un fuerte deterioro del medio natural y de las condiciones ambientales en la ciudad de México que, como es sabido, es una de las ciudades más contaminadas del mundo.

b) La política de petróleo barato seguida por el Estado hizo que la industria mexicana fuera incapaz de competir en los mercados internacionales eficientemente y evitó que la industria se reconvirtiera tecnológicamente ya que su dinamismo era basado en el subsidio energético y no en una competitividad tecnológico-productiva. La industria permaneció tecnológicamente rezagada.

c) La falta de ajuste en el precio interno del petróleo dio lugar a un fuerte déficit fiscal y a una voluminosa deuda externa, ya que el gobierno recargó al presupuesto la diferencia entre el precio interno y el internacional. Adicionalmente, la economía mexicana llegó a ser completamente dependiente del petróleo y de las fluctuaciones en el precio internacional de éste, lo cual degeneró en la crisis económica de la década de 1980.

En 1973, aparecieron nuevas expectativas para México al descubrirse nuevas reservas de petróleo en los Estados de Tabasco y Chiapas, con lo que México recuperaría su importancia internacional como exportador de 
petróleo. Los nuevos descubrimientos hicieron que las reservas mexicanas de petróleo se incrementaran de 5,432 millones de barriles en 1973 a 72,000 millones de barriles en 1981. Como consecuencia, la inversión pública en el sector petrolero fue substancialmente incrementada pasando de un $15.5 \%$ a un $41.5 \%$ en el mismo período. Igualmente, la participación del petróleo en la formación del PNB creció de $4.3 \%$ al $10 \%$ en dicho período. Las nuevas reservas situaron a México, de acuerdo con el discurso oficial, como el cuarto depositario mundial de petróleo y gas (Grayson, 1988:P.26).

Desde el hallazgo de las nuevas reservas, México ha basado su política económica y sus relaciones exteriores en su potencial petrolero. Primeramente, en la medida en que había petróleo en abundancia, el país utilizaría el consumo de éste a un precio bajo junto con sus ganancias en el comercio exterior para financiar la industrialización y diversificación de la economía. Así, se esperaba que la industria generaría el $85 \%$ de los ingresos externos de la nación para 1990 mientras que sólo un $15 \%$ se derivaría del petróleo (Ibid:PP.27-28).

No obstante, desarrollar los nuevos depósitos requirió de nueva inversión lo cual se constituyó en el principal obstáculo para el país. La solución a este problema se encontró en la banca internacional tanto pública como privada. Los nuevos descubrimientos de depósitos abrieron nuevas oportunidades para la banca internacional para colocar sus excedentes financieros, y por lo tanto, pusieron sus recursos a disposición de las autoridades mexicanas en condiciones favorables. Con el fin de atraer al capital extranjero, el gobierno de López Portillo (1976-82) anunció que los nuevos hallazgos convertían a México en el cuarto depositario mundial de reservas, mientras que un reporte de la compañía estatal PEMEX admitió en 1982 que México era en realidad el número quinto a nivel mundial (en: Latin America Weekly Report, Noviembre 5, 1982, P.3).

Como resultado de la estrategia propagandística, hubo un sorprendente incremento de la deuda mexicana más allá de las posibilidades de pago del país, la cual creció de 22.9 mil millones de dólares en 1977 a 85 mil millones en 1982, representando cerca del 60\% del PNB y $40 \%$ del valor de las exportaciones. El excesivo endeudamiento parece haber sido producto de cálculos aventurados sobre el crecimiento de la economía y del precio internacional del petróleo. Fue también producto del incremento en las tasas internacionales de interés. 
El presidente López Portillo, motivado por el aumento en el precio del petróleo, creyó que el mismo mostraría una tendencia constante y que el país multiplicaría sus ganancias en un plazo relativamente corto. En realidad, los ingresos provenientes del petróleo se incrementaron de 340 millones de dólares en 1976 a 12 mil millones dólares en 1980, lo cual daba base al razonamiento del gobierno. Sin embargo, los precios decayeron fuertemente durante la década de 1980 y el Estado mexicano empezó a sufrir una fuerte crisis fiscal que forzó al gobierno a incrementar aún más la deuda externa del país. Para 1981 el gobierno ya había alcanzado un alto nivel de endeudamiento externo y era abatido por una crisis de pago, lo cual obligó al presidente López Portillo a declarar en 1982 una moratoria de la deuda, poniendo a la comunidad financiera internacional en una alerta roja y forzándola a la búsqueda de un arreglo particular que permitiera evaporar el peligro de un shock financiero internacional.

El ajuste de la economía mexicana fue ignorado durante la década de 1970 en la medida en que la bonanza petrolera creó una cortina de humo sobre un desarrollo económico ficticio el cual resultó difícil de sostener en el largo plazo. En realidad, en 1976 el país sufrió una fuerte crisis fiscal y desequilibrio de la balanza de pagos con un déficit comercial cercano a los 4 billones de dólares, por lo que se hizo un intento de ajuste económico mediante la firma de un acuerdo de extensión ampliada con el FMI, pero el hallazgo de nuevas reservas de petróleo por esos años le permitió a México evitar la aplicación de un ajuste neoliberal severo que habría afectado las condiciones de vida de los mexicanos (Véase, Villarreal, 1981:P.5). Por lo que la economía incrementaría su dependencia de las ventas del petróleo. Así, contrariamente a lo esperado, el país había incrementado su dependencia del petróleo ya que, mientras que los ingresos provenientes del petróleo en 1977 representaban un 27\% de las exportaciones, para 1983 éstos representaban un $70 \%$ lo cual hacía a la economía vulnerable de las fluctuaciones en el precio internacional del crudo.

\section{El petróleo como instrumento de la política exterior}

El apogeo de la industria petrolera también trajo como resultado un resurgimiento de México como actor importante en las relaciones interna- 
cionales. En la medida en que el país atraía el interés de las instituciones financieras internacionales, de la banca privada y de líderes políticos ansiosos de ser parte del desarrollo petrolero mexicano, el presidente López Portillo trató de configurar el liderazgo de su país en la política mundial. En este contexto, México fue un apoyo clave para la revolución sandinista en Nicaragua y brindó soporte político, sobre todo a un nivel declarativo, al FMLN en El Salvador en su lucha contra la oligarquía y el ejército de ese país, desafiando de esa manera el intervencionismo estadounidense en Centroamérica. En la medida en que el conflicto centroamericano se agravó, México se convirtió en uno de los actores principales en la búsqueda de una solución pacífica a dicho conflicto, promoviendo el diálogo entre el gobierno sandinista y el de los Estados Unidos y creando junto con Venezuela, Colombia y Panamá en 1983 el Grupo de Contadora como una alianza latinoamericana para promover la negociación y la paz en Centroamérica.

Por otro lado, destaca el hecho de que aunque México se convirtió en un exportador mundial de petróleo, rehusó integrarse al grupo de países de la OPEP. La integración a la OPEP habría implicado coordinar la política petrolera del país en el marco de las decisiones tomadas por dicho cartel. México encontró más rentable vender su petróleo fuera del marco de las decisiones de la OPEP mientras que se beneficiaba de los precios internacionales fijados por dicho cartel. Los gobiernos mexicanos consideraban inconveniente para el interés nacional del país el formar parte de instituciones que podrían comprometer su libertad de maniobra en las relaciones internacionales (Grayson, 1988:P.108). De esta forma, México ha procurado evitar relaciones conflictivas tanto con los países desarrollados como con los países en desarrollo. Su rechazo a la membresía de la OPEP estuvo determinada por esta clase de interpretación de su política exterior.

No obstante, la principal razón para este comportamiento parece ser su dependencia de las inversiones estadounidenses y del mercado de este país para sus exportaciones, por lo que México ha procurado no incomodar los intereses económicos norteamericanos. En 1978, por ejemplo, México exportó 458 millones de dólares a los Estados Unidos dentro del Sistema General de Preferencias otorgado por dicho país a países en desarrollo. Igualmente, el desarrollo de la industria de la maquila con inversiones norteamericanas ha venido cobrando una remarcada importancia para la 
economía mexicana, en la que se emplean cerca de medio millón de mexicanos y se generan alrededor de 7 billones de dólares por año. Participar en un organismo como la OPEP, hostil a los intereses norteamericanos podía poner en peligro los intereses económicos y comerciales de México en aquel país, y en consecuencia, ser objeto de sanciones económicas y políticas, tal como les sucedió a Venezuela y a Ecuador en 1973 cuando la OPEP decretó un embargo contra Estados Unidos por su apoyo a Israel en la guerra de Yom Kippur. Represalias comerciales similares contra México habrían sido devastadoras para la economía mexicana dada la dependencia de México del mercado estadounidense, pues un $90 \%$ de las exportaciones de hidrocarburos en la década de 1970 se dedicaban al mercado de los Estados Unidos. Así que prudencia y autolimitación serían el mejor curso a seguir en las relaciones políticas y comerciales con el gobierno norteamericano.

Otro aspecto que explica la actitud mexicana frente a la OPEP es la importancia comercial de Israel para México. Desde finales de la década de 1970, México ha sido uno de los principales proveedores de petróleo de Israel, arriba de los $50.000 \mathrm{~b} / \mathrm{d}$. Adicionalmente, México ha tenido una ventaja comparativa sobre los países de la OPEP en materia petrolera dada por su larga experiencia en el manejo de dicha industria así como por la estabilidad política que desde tiempos de Cárdenas vivió el país, por lo menos hasta 1993, período que concluyó con la administración de Carlos Salinas de Gortari, lo cual convirtió a México en un proveedor internacional confiable.

En 1979, el presidente López Portillo presentó un Plan Global de Energía ante las Naciones Unidas que buscaba aliviar el impacto del incremento de los precios del petróleo sobre los países importadores. En su discurso el presidente señaló que:

«la injusta distribución de petróleo y gas había ampliado el abismo entre naciones productoras y consumidoras, dando lugar a la amenaza de un conflicto global, así -el presidente señaló que-, a pesar de que México simpatizaba con la lucha de las naciones para revalorar sus materias primas en el mercado internacional, consideraba que era imperativo desmantelar un sistema (el petrolero) que operaba en detrimento de todos".

(Grayson, Op.cit:P.110) 
El plan del presidente comprendía los siguientes elementos:

- Garantizar la soberanía de cada nación sobre sus propios recursos naturales.

- Proveer de asistencia financiera y técnica para racionalizar la exploración, producción, distribución, consumo y conservación de petróleo y otras fuentes de energía.

- Desarrollar sistemáticamente otras fuentes potenciales de energía tanto tradicionales como no convencionales.

- Que todas las naciones elaboren su plan nacional de energía en forma compatible con el plan global.

- Resolver en el corto plazo los problemas energéticos de los países del tercer mundo.

- Crear un fondo internacional para financiar las necesidades de energía tanto de corto como de largo plazo de los países menos adelantados.

- Asegurar a los países en desarrollo un acceso rápido a la tecnología energética moderna.

- Crear una Organización Internacional de energía.

(Grayson, Op.cit: P.111)

El plan global de energía presentado por México ante las Naciones Unidas fue cálidamente recibido tanto por los países industrializados como por los países en desarrollo no productores de petróleo. Ambos sufrían el embate causado por el incremento en el precio del petróleo bajo el control de la OPEP. En el marco de dicho plan, México participó conjuntamente con Venezuela en 1980 en un programa de suministro de petróleo, en condiciones concesionales, a los países de Centroamérica y el Caribe, programa conocido con el nombre de «Pacto de San José», el cual se ha venido renovando cada año.

Los países de la OPEP, sin embargo, reaccionaron enconadamente contra dicho plan por considerarlo contrario a sus intereses políticos y económicos. Los miembros de la OPEP creían que la política mexicana era contraria a los intereses del tercer mundo, que al darle precedencia al tema de la energía -al margen de otros temas como son comercio y desarrollo, cooperación económica-, se corría el peligro de dividir a los países del tercer mundo en el denominado diálogo Norte-Sur entre países productores y países importadores de petróleo. También argumentaban, los países miembros 
de la OPEP, que ellos habían venido canalizando parte de las ganancias obtenidas del comercio del petróleo mediante programas de ayuda a países en desarrollo como forma de compensar a estos países por el incremento en los precios. No obstante, aunque los países miembros de la OPEP hicieron un aporte adicional de 800 millones de dólares a mediados de 1979, el incremento en el precio del petróleo significaba que retornarían hacia los países en desarrollo solamente $\$ 1$ por cada $\$ 10$ obtenido de las ventas de petróleo, por lo que los países en desarrollo seguirían cargando con una enorme factura petrolera (Grayson, Ibid: P.109). Otro elemento característico de la ayuda económica de la OPEP lo ha constituído su concentración regional, especialmente, en los países árabes no productores de petróleo y en los países mediterráneos.

La política exterior de México, sin embargo, como toda política, ha estado determinada fundamentalmente por la influencia de factores internos y por los constreñimientos emanados del ambiente externo, pero, especialmente, por el desempeño real de la economía nacional. Así, conforme se desvanecía el abanico ilusorio de convertir a México en un país industrializado para el año 2000, debido al advenimiento de la crisis de la deuda externa durante la década de 1980 y a las fuertes fluctuaciones del precio del petróleo en 1982, 1985 y 1986, los gobiernos mexicanos no sólo se han visto forzados a hacer ajustes en su política exterior sino que también se han visto forzados a reducir el rol protagónico de México en la política internacional, sobre todo su rol activo en el Tercer Mundo.

En 1980 México empezó a sufrir los efectos de la peor crisis económica de su historia. Por casi cinco décadas consecutivas México había experimentado tasas de crecimiento económico anual de alrededor del 6.7\%. En 1982, sin embargo, el crecimiento del PNB se volvió negativo por primera vez desde 1920 y, desde entonces la economía ha estado en una fase recesiva (Rojas, 1991:P.169). La bonanza petrolera había sido sobrepasada por el crecimiento de la deuda externa. Para 1986, los ingresos anuales provenientes del petróleo fueron inferiores por primera vez al pago de los intereses de la deuda externa (Ibid:P.177). Esta nueva realidad económica hace que los gobiernos mexicanos procuren un cambio substancial en la política exterior del país, dejando de lado la política tradicional basada en el apoyo al nacionalismo revolucionario y a la solidaridad con el Tercer Mundo, adoptando en cambio una política orientada a insertar a México 
más competitivamente en la economía mundial en general, y en el mercado con sus vecinos de norteamérica, en particular (Eschbach, 1991:P.171).

En la medida en que México comienza ver erosionadas sus ganancias provenientes del comercio del petróleo, como resultado tanto de la inestabilidad del mercado, caída de precios y caída inclusive en sus propias reservas de petróleo y gas natural, los gobiernos, desde Miguel de la Madrid, se han visto forzados a adoptar una actitud más cooperativa con la OPEP con el fin de estabilizar el mercado y así reducir sus pérdidas. Dentro de este nuevo marco, México participa desde 1983 como miembro observador en las reuniones de la OPEP, donde promueve el intercambio de información y mayores vínculos con los países miembros del cartel. Igualmente, desde 1983, sin ser miembro, México ha venido adhiriéndose al sistema de cuotas de la OPEP, siempre dentro de su interés por estabilizar el mercado mundial. La buena disciplina comercial de México, bien en línea con las políticas de la OPEP, v.g, ventas bajo contrato, eliminando precios de descuento y cumpliendo las metas de exportación, le ha ganado la reputación de ser el mejor miembro de la OPEP (Grayson, 1988:P.117), a pesar de no ser miembro de dicha organización; lo cual constituye un viraje político de 180 grados si se le compara con la práctica seguida anterior a 1982.

Similar moderación fue adoptada por México con respecto a su política exterior en Centroamérica, donde primeramente, México siguió una política unilateral dirigida a reestablecer la paz en la región, posteriormente, durante el gobierno de Miguel de la Madrid, se sigue un modelo de negociación multilateral a través del Grupo de Contadora y el denominado Grupo de Apoyo, ambos articulados por la diplomacia mexicana y, finalmente, durante el gobierno de Salinas de Gortari se siguió una política estricta de apoyo a los esfuerzos de paz emprendidos por los presidentes de la región. El protagonismo político mexicano en la región fue reemplazado por un protagonismo de tipo económico donde México busca convertirse en el modelo de desarrollo económico, el cual es inspirado en principios neoliberales, modelo que la región debería seguir. Paralelamente, México otorga cooperación económica a los países de la región, ya sea colectivamente o en forma individual. El Acuerdo Marco de Tuxtla Gutiérrez de principios de la década de los 90 s instituyó el nuevo marco de relaciones económicas y políticas entre México y Centroamérica (Eschbach, Op.cit:P.176). 


\section{Industria petrolera, crisis económica y ajuste estructural desde 1983}

Hasta 1981, los gobiernos mexicanos rehusaron hacer ajustes en la economía por lo que las distorsiones económicas se acumularon. El modelo de sustitución de importaciones seguido por México hasta principios de la década de 1980 encontró sus límites a finales de la década de 1970. La industrialización que surgió de dicho proceso no fue autosuficiente y tuvo que ser financiada con divisas obtenidas del comercio exterior de bienes agrícolas y materias primas así como con deuda externa.

La existencia de créditos blandos en el mercado internacional y el nuevo stock de reservas de petróleo descubierto durante la década de 1970, facilitó las cosas e hizo que la crisis se difiriera para años más tarde. Como señala Raúl Rojas (1991:P.170), el endeudamiento externo y el petróleo le permitió al viejo y enclenque modelo de acumulación sobrevivir por unos cuantos años más. Para 1981, sin embargo, el largo ciclo de crecimiento económico basado en deuda externa, petróleo e intervencionismo estatal había llegado a su fin. El resultado fue una fuerte crisis económica y la consiguiente pérdida de confianza sobre la viabilidad del modelo económico y sobre las posibilidades de estabilizar la economía en el corto plazo, con una deuda externa que sobrepasaba los 85 mil millones de dólares.

Como resultado de la pérdida de confianza sobre la estabilidad de la economía, el país sufrió una fuerte fuga de capital. En 1980, por ejemplo, la fuga de capital fue de $\$ 2,958$ billones y para 1981, la cifra era de $\$ 10,914$ billones, la cual representaba un 3.4\% del PNB. Debido a la gravedad del problema, en 1982, el gobierno de López Portillo trató de implementar un urgente programa de estabilización económica, imponiendo controles a las importaciones, incrementando las tasas de interés en alrededor del 70\% para contener la fuga de capital e inclusive devaluó el peso con el fin de contener la inflación de alrededor del $100 \%$ y favorecer las exportaciones (Mirón y Pérez, 1988:P.126, y Rojas, Op.cit:P.173). No obstante, dichas medidas no detuvieron la crisis, al contrario, crearon nuevas dificultades económicas e impusieron nuevas penalidades a la población. El valor real del salario decayó en un $25 \%$ en 1981, cerca de 150.000 trabajadores perdieron sus empleos, la fuga de capital continuó y las instituciones financieras internacionales le suspendieron el financiamiento al país en 1982. 
Con el fin de detener esas tendencias desestabilizadoras en la economía así como de recuperar imagen, el presidente Portillo se vio forzado a nacionalizar la banca, para así, asegurar el control de los movimientos de capital y reestablecer la confianza sobre el manejo de la economía. El mismo año (1982), México también se declaró insolvente para servir su deuda externa, convirtiéndose en el segundo país latinoamericano que declaraba una moratoria en el pago de la deuda externa, justamente un año después de Costa Rica. Sin embargo, debido al hecho de que México, además de ser una potencia petrolera, era el segundo país en la escala de países altamente endeudados justo después de Brasil, y por consiguiente, con capacidad de poner en jaque a la comunidad financiera internacional con una posible amenaza de no pago, la banca internacional evitó correr el riesgo de castigar a México cortándole los flujos de capital y sometiéndolo a adoptar políticas de estabilización económica que fueran inaceptables para el gobierno mexicano. Ese «restrain» de los acreedores refleja, en gran medida, la importancia del petróleo mexicano en las relaciones internacionales.

Contrario a como lo hizo con Costa Rica y años más tarde con Perú, cuyas deudas aunque superiores a la mexicana en términos per capita, eran insignificantes en términos absolutos o en relación a la deuda global del Tercer Mundo, la política seguida hacia México por la Banca Internacional fue de cooperación. Como primer acto, cerca de 526 bancos de alrededor del mundo donaron $\$ 5$ billones como parte de una operación de rescate de $\$ 8$ billones (Castle, 1995:P.20). Seguidamente, en agosto de 1983, la banca internacional aceptó reestructurar $\$ 20$ billones de deuda de corto plazo, difiriendo el pago a 8 años después de lo originalmente contratado. Dicha reestructuración fue seguida por una segunda con la que se difirió el pago de otros $\$ 10$ billones que tenían como fecha límite 1985. El gobierno de los Estados Unidos vino a jugar el rol del Samaritano al asistir a México no sólo mediante el otorgamiento de aproximadamente el $80 \%$ del total de los créditos que se le giraron al país, sino también, mediante el rol protagónico jugado por el Banco de la Reserva Federal y el Departamento del Tesoro para reunir el apoyo de la banca internacional tanto privada como pública (véase, Lustig, 1997:P.43). Los nueve principales bancos estadounidenses eran acreedores de cerca del. 50\% de la deuda mexicana en 1982 (Ibid:P.45), lo que explica, en parte, el protagonismo del gobierno estadounidense. 
El gobierno de López Portillo marcó el cierre de una era de desarrollo económico basado en la sustitución de importaciones y en la intervención del Estado como instrumentos de política económica orientados a promover la industrialización del país y el crecimiento económico. Con Miguel de la Madrid, Salinas de Gortari y Ernesto Zedillo, sucesores de Portillo, México entra en la era del ajuste estructural, donde se hace un replanteamiento de las políticas económicas del pasado y se redefine un nuevo marco de relaciones económicas basadas en el comercio exterior y en la liberalización de la economía.

A partir del gobierno de Miguel De la Madrid, la política mexicana se ha centrado en torno al ajuste estructural de la economía y en una política exterior orientada a crear condiciones externas para la promoción y colocación de las exportaciones mexicanas. Presionado por el FMI y el Banco Mundial, el gobierno de De la Madrid, buscó estabilizar la economía mediante la aplicación de programas rigurosos de estabilización económica orientados a reducir el déficit fiscal del 16.5\% del PNB en 1982 a 3.5\% en 1985 y privatizar un conglomerado de empresas públicas (de unas 1,155 en 1982) calificadas como ineficientes, de las cuales en 1985 se privatizaron 236 (Rojas, Op.cit:P.176).

Adicionalmente, la economía mexicana tenía que liberalizarse con el fin de asegurar la entrada de México al Acuerdo General de Aranceles y Comercio, GATT y al mercado del norte, NAFTA, formado por Estados Unidos y Canadá al cual México se integró en 1993. La integración de México al GATT era una de las grandes aspiraciones de lós gobiernos norteamericanos como el quid pro quo para ampliar las relaciones económicas y comerciales con México en una forma mas integrada de sus economías al estilo NAFTA (Véase Villarreal, 1981:PP.35-36).

Hasta 1980, México había rehusado integrarse al GATT. A criterio del presidente López Portillo, no era oportuno para México integrarse al GATT o adherirse a cualquier código antitarifario (Randall, 1989:P.178). De igual forma, el Presidente Portillo había rechazado categóricamente «la posibilidad de una asociación económica regional» con los Estados Unidos debido a las asimetrías en los niveles de desarrollo de los dos países, lo que condenaría a México a «extraer y exportar a perpetuidad materias primas para su aprovechamiento por sociedades mas avanzadas" (Villarreal, 1981:P.35). Sin embargo, a medida en que los Estados Unidos empezó a 
variar los términos del intercamibio comercial con México imponiéndole ciertos criterios de reciprocidad, el gobierno mexicano se vio forzado a acelerar las negociaciones para su adhesión al Acuerdo general. La adhesión al GATT, la cual se hizo efectiva en julio de 1986, era, además, indispensable dado el nuevo carácter que estaba adquiriendo el modelo de desarrollo mexicano basado en el comercio exterior, lo cual hacía necesario que México contara con instrumentos jurídicos (tales como la prueba del daño y la capacidad de imponer controles provisionales a las importaciones por razones de balanza de pagos) para defender su comercio exterior y su política económica. La adhesión al GATT era también importante para que México pudiera participar en la Ronda Uruguay.

El proceso de liberalización económica también ha supuesto revertir la nacionalización bancaria y abrir las puertas a la inversión extranjera en el sector petrolero. En 1990 el gobierno de Salinas anunció que privatizaría parte de los bancos comerciales con el fin de hacer la economía más competitiva en el contexto del nuevo modelo de desarrollo hacia fuera seguido por el país. Con respecto a la industria petrolera, hasta 1992, México había rehusado abrir dicha industria a la inversión extranjera. El gobierno de Salinas de Gortari, sin embargo, entendió que el futuro económico y las posibilidades que tiene México para integrarse exitosamente en la competencia internacional por los mercados depende, en gran medida, de la remoción de obstáculos internos que impiden que la economía opere competitivamente, y eso incluía abrir la industria del petróleo a la inversión extranjera. Por otro lado, conforme el país estrecha sus vínculos comerciales con sus vecinos norteños en el marco de NAFTA, el monopolio de la actividad petrolera bajo el control de PEMEX, se volvía insostenible $y$, por lo tanto, el sector debía de ser abierto a las inversiones estadounidenses. NAFTA incluye provisiones en materia de inversión extranjera entre las que figuran el principio del trato nacional a dichas inversiones y la eliminación de requisitos sobre contenido local. Es importante señalar, sin embargo, que la apertura que se esta operando en la industria petrolera mexicana no afecta el monopolio de PEMEX sobre la producción. En 1995 el Congreso de México reformó el artículo 27 de la Constitución, por lo que ahora se permite a la inversión privada, extranjera o local, invertir en servicios de transporte, almacenaje y distribución de petróleo y gas natural, pero el monopolio del Estado sobre la producción se mantiene incólume. 
La nueva normativa sobre la materia permite a los inversionistas privados construir, operar y poseer nuevos gasoductos, facilidades de almacenaje y libre concurrencia en el mercado para la venta y adquisición de gas natural. La Comisión Reguladora de Energía (CRE) ya ha autorizado alrededor de quince permisos para construir mas de 250 millas de gasoductos y se esperan inversiones hasta por $\$ 500$ millones para construir unas 1000 millas de gasoductos para el transporte de gas natural (Canning House, 1998:P.16).

La apertura de la industria del petróleo ha sido programada para que se lleve a cabo gradualmente por un período de 10 años. El acceso a tecnología moderna en el sector, como consecuencia de la inversión extranjera, va a tener probablemente un efecto expansivo de la producción petrolera la cual ayudaría a corregir déficits en la balanza de pagos, aunque la industria per se ya no será exclusivamente mexicana. Adicionalmente, la apertura de la industria del petróleo a la inversión extranjera va a tener seguramente un efecto significativo en la reducción de la multimillonaria deuda de PEMEX y en el déficit del gobierno.

En general, hasta 1994, se creía que México había llevado a cabo una exitosa política de ajuste estructural de su economía. En realidad, hasta ese año se habían obtenido resultados económicos relevantes según se observa en los siguientes indicadores:

- El déficit fiscal fue reducido de $17 \%$ del PNB en 1982 a «0» en 1990 , y en 1992 y 1993 hubo un superávit de $1.6 \%$ y $0.7 \%$ respectivamente.

- El régimen tributario fue rediseñado para promover tanto la inversión como el ahorro interno.

- La dependencia de la economía de las exportaciones de petróleo fue drásticamente reducida de un $75 \%$ en 1982 a un $14 \%$ en 1993.

- La inflación fue reducida de cerca del $160 \%$ en 1987 a un estimado del $8 \%$ en 1994.

- Finalmente, el tamaño del sector público se redujo mediante un programa de privatización de las empresas del Estado, pasando de 1,155 en 1982 a 210 en 1994.

(Rojas, 1995:P.1)

A pesar de los referidos logros, la crisis política y económica que enfrentó México en 1994 y 1995, puso en tela de duda la sostenibilidad de la estabilidad económica y la efectividad misma del proceso de ajuste de la economía. En efecto, a pesar de los aparentes logros del presidente Salinas 
en materia económica, en enero de 1994, se dio a conocer sobre el alzamiento en armas de sectores de la comunidad indígena en el Estado de Chiapas agrupados en el Ejército Zapatista de Liberación Nacional, quienes denunciaban las injusticias sociales a las que se hayan sometidas las comunidades indígenas, la injusta distribución de la tierra y una plétora de corrupción política producto de décadas de gobiernos Priistas. Sumada a la crisis de Chiapas, durante 1994 afloraron las contradicciones políticas en el partido de gobierno desencadenando en una de las peores crisis políticas conocidas en la historia contemporánea de México. 1994 era un año electoral y era normal que se agitaran los ánimos, pero no a los niveles de violencia como sucedió. El 23 de marzo de ese año el candidato presidencial del PRI, Luis Donaldo Colosio fue asesinado poniendo a México al borde de una crisis político-institucional y arrojando dudas sobre la transparencia del proceso electoral. Colosio estaba fuertemente comprometido con las ideas de reforma del aparato político mexicano y por ello su vida fue segada por fuerzas tradicionalistas acostumbradas a vivir de la corrupción política bajo la égida del poder del Estado. La crisis fue parcialmente sobrepuesta con el nombramiento de Ernesto Zedillo como nuevo candidato quien llevaría al PRI a una nueva victoria electoral en el mes de agosto de 1994. Sin embargo, las elecciones no resolvieron los conflictos políticos y el 28 de septiembre del mismo año, fue asesinado el Secretario General del PRI José Francisco Ruiz Massieu, asesinato en el cual apareció implicado como autor intelectual Raúl Salinas, hermano del ex presidente Carlos Salinas. Investigaciones posteriores demostraron los vínculos de Raúl. Salinas con negocios ilícitos, entre ellos, venta de influencias, lavado de dineros provenientes del narcotráfico con cuentas bancarias en el exterior que sobrepasan los noventa millones.

Sumado a la crisis política, el 20 de diciembre de 1994, México sufría una fuerte crisis en su sistema financiero, dando lugar a una pérdida de credibilidad sobre la estabilidad de la economía y generando una salida masiva de capitales. Ante tal situación, el gobierno se vio forzado a devaluar el peso en un $14 \%$. Antes de la forzada devaluación el peso se cotizaba a 3.50 por dólar, sin embargo para finales de enero de 1995, la cotización se ubicó en 7.67 por dólar, por lo que los mexicanos vieron como de la noche a la mañana sus estándares de vida, ya de por si maltrechos, se deterioraban aún más con una inflación de alrededor del $30 \%$ que redujo el valor de los 
salarios. Igualmente, como resultado de la crisis financiera las tasas internas de interés aumentaron en casi un $150 \%$, profundizando el estado recesivo de la economía que el país venía sufriendo desde el gobierno de Salinas. El crecimiento económico en 1993 fue de apenas el $0.4 \%$ y se mantuvo estancado durante 1994 y 1995 y sólo empezó a dar signos de recuperación durante 1996, luego de una fuerte inyección de nuevos recursos externos proveídos por el gobierno de los Estados Unidos y la banca internacional (préstamo de garantía de $\$ 40.000$ millones otorgados por la administración Clinton, FMI, Banco Mundial y otros gobiernos amigos) en apoyo al peso, y una nueva reestructuración de la deuda externa, todo ello garantizado con la factura petrolera. Véase cifras en el cuadro que se despliega abajo.

La crisis en cuestión fue consecuencia, según Jaime Ros (1995:P.136), tanto de una falla de mercado como de una falla de gobierno. Es decir, inversionistas extranjeros que habían sido malamente informados sobre la estabilidad económica y monetaria de México se vieron forzados a retirar sus capitales para protegerse de las pérdidas producidas por una moneda sobrevaluada. La falla política o de gobierno es atribuida por dicho autor, por un lado, por la incapacidad del gobierno de hacer congruente la política monetaria con el proceso de liberalización comercial, es decir, que el peso sobrevaluado contrariaba la política de expansión comercial. Por otro lado, la falla de gobierno está asociada a la política impositiva ya que debido a una percepción sobre el auge de la inversión extranjera en el país, el gobierno había venido reduciendo los impuestos al consumo en un momento en que el ahorro interno decaía, de tal manera que al no haber una sólida base de ahorro interno, la estabilidad de la economía descansaba peligrosamente en los movimientos de capital extranjero los cuales son extremadamente susceptibles a la percepción que los inversionistas tengan sobre la estabilidad de la economía en el corto plazo. 
México: Indicadores Económicos

\section{Pronóstico}

$\begin{array}{lrrrrrrrr} & 1991 & 1992 & 1993 & 1994 & 1995 & 1996 & 1997 & 1998 \\ \text { PIB (\%) } & 3.6 & 2.6 & 0.4 & 3.5 & -6.9 & 5.1 & 7.1 & 5.0 \\ \text { Inflación (\%) } & 18.8 & 11.9 & 8.0 & 7.1 & 52.0 & 34.4 & 20.0 & 14.0 \\ \text { Balance Comercial (\$bn) } & -9.0 & -20.0 & -14.8 & -18.5 & 5.3 & 5.0 & 0.6 & -5.0 \\ \text { Balance fiscal (como \% del PIB) } & -0.5 & 1.6 & 0.7 & -0.7 & 1.0 & 0.4 & 0.0 & -1.3 \\ \text { Cuenta Corriente (\$bn) } & -14.8 & -24.8 & -23.3 & -29.8 & -0.7 & -1.9 . & -8.5 & -15.7 \\ \text { (como \% PIB) } & -5.1 & -7.4 & -6.5 & -8.1 & -0.3 & -0.6 & -2.1 & -3.5 \\ \text { Reservas Externas (Sbn) } & 122.0 & 133.2 & 153.5 & 162.4 & 174.0 & 169.4 & 169.1 & 156.0 \\ \text { Tipo de Cambio (Pesor/\$) } & 3.0 & 3.1 & 3.1 & 4.9 & 7.67 & 7.8 & 8.1 & 8.7\end{array}$

Fuente:JP Morgan, en Canning House, 1998:P.11. $(\$ b n=$ billones de dolares $)$. 
La crisis económica fue también un producto de lo que Thomas D. Rojas (1995:P.1) denomina la disfuncionalidad del proceso neoliberal que ha empujado a un régimen autoritario a emprender reformas económicas injustas y que para cuya realización ha tenido que respetar los privilegios tradicionales dados a los clientes y cuadros del partido, quienes han operado y se han beneficiado del sistema corporativo de éste y de su patrocinio político y económico, y que ahora obstaculizan las reformas por que no se conforman con renunciar al sistema de prebendas políticas. Esta interpretación parece ser la base para entender la ola de asesinatos políticos cometidos en 1994.

El gobierno de Ernesto Zedillo ha tratado de darle continuidad al proceso de liberalización económica vendiendo, por ejemplo, parte de las industrias petroquímicas que han estado bajo control de PEMEX, pero evitando la venta de esta empresa per se. En lo político, su gobierno ha buscado forjar un consenso y diálogo nacional con los partidos de oposición, incluyendo los alzados en armas en Chiapas, y ha procurado realizar reformas políticas, sin embargo ha sido incapaz de superar la denominada disfuncionalidad del proceso de reforma.

A nivel económico, el gobierno de Zedillo se ha visto forzado a adoptar medidas duras de estabilización y de manejo de la crisis. El pueblo mexicano creía que ese tipo de medidas, propias de los años 80 s, eran cosa del pasado. Salinas de Gortari les había vendido la idea de un México acercándose cada vez más al grupo de países desarrollados con la integración de México a la Organización para la Cooperación y Desarrollo Económico (OCDE) en la que se agrupan los países desarrollados, la integración al NAFTA y la participación del país en las relaciones económicas en el marco de las conferencias de los países de la denominada Cuenca Pacífica, en la que participan Estados Unidos, Japón, Australia, Nueva Zelandia y los nuevos países industrializados de Asia.

La crisis política y económica de 1994-95 vino no sólo a desvanecer sino que, además, a desmitificar dichas aspiraciones. La realidad es que México sigue siendo un país en desarrollo, o quizás más precisamente, un país semi periférico (que es la posición en que algunos autores ubican a países con estatus de desarrollo intermedio entre el desarrollo y el subdesarrollo, tales como México, Brasil, o Argentina etc.) y que las políticas de liberalización económica no sólo han reducido su nivel de autonomía en 
las relaciones internacionales sino que lo han vuelto mucho más dependiente de cuanto sucede en el resto del mundo, especialmente, en los países desarrollados, y en particular, en sus nuevos socios en NAFTA, donde se destina el $81 \%$ del comercio mexicano. Aunque después de la crisis México ha venido mostrando un crecimiento extraordinario, según se desprende de la recuperación del PIB a partir de 1996, y del crecimiento de las exportaciones que en 1997 registraron $\$ 110.4$ mil millones de dólares, de las cuales un $85.8 \%$ corresponden a bienes manufacturados, una cifra récord que en gran medida refleja el efecto de la devaluación monetaria sufrida en los anos de la crisis, pero no obstante, extraordinaria sobre todo si se le compara con el ano de 1988 en que las manufacturas solo aportaban $\$ 21$ mil millones.

La estabilidad económica y el desarrollo del país ahora deperden menos de la política económica seguida por el gobierno y más de factores externos, sobre todo, de la disposición del capital extranjero de volverse a reubicar en el país y de las posibilidades de nuevos créditos del gobierno estadounidense y de la banca internacional que permitan mantener la credibilidad de la moneda y de la reforma económica.

El éxito de la estabilidad económica y del proceso de ajuste estructural tambiên depende de la capacidad del gobierno para contener el deterioro de la estabilidad política y resolver el problema de la corrupción que ha desvalorizado la política mexicana. Posiblemente el triunfo de Cuauhtemoc Cardenas el 6 de julio de 1997 de la Gobernación de la ciudad de México sea un punto en esa dirección. El logro de una estabilidad duradera también reclama una transición política de México del autoritarismo priista hacia la democracia que permita que otros partidos políticos puedan disfrutar de condiciones políticas y jurídicas tanto a nivel estatal como federal para competir en una lucha democrática por el poder del Estado. Un México más democrático indudablemente va a redundar en el mejoramiento de las condiciones de vida de los mexicanos, al menos en lo que respecta a la participación política. Pero el mejoramiento de las condiciones de vida también requiere del mantenimiento de la estabilidad económica y de la aplicación de una política de ajuste económico cuyos costos no recaigan de manera desproporcionada sobre las capas más endebles de la población. 


\section{Conclusiones}

1.- La decisión de México de expropiar y nacionalizar la industria del petróleo en 1938, no sólo representó una acción temprana de un país en desarrollo por afirmar el control y explotación de sus recursos naturales en pro de su desarrollo económico, sino que además, constituyó una evidencia tangible de que, cuando existe un consenso nacional, es posible establecer limitaciones al poder económico e influencia política de los agentes económicos externos que tienen como marco de sus operaciones la economía nacional, en este caso, la mexicana.

2.- Desde la nacionalización de la industria, México ha utilizado el petróleo como motor del desarrollo industrial y del crecimiento económico. La existencia de petróleo en cantidades abundantes, si bien tuvo un efecto positivo en términos del crecimiento industrial, también tuvo un efecto negativo ya que la economía se volvió fuertemente dependiente de los ingresos de exportación de petróleo y, además, debido a que se creyó que los ingresos provenientes del petróleo siempre serían crecientes, los gobiernos evitaron hacer ajustes en la economía. La economía no se diversificó al nivel deseado y las empresas no hicieron ajustes tecnológicos que les permitiera ganar una mayor competitividad en el mercado internacional. El efecto de la falta de ajuste fue la crisis económica que desde 1980 ha vivido el país y el creciente endeudamiento externo que ha limitado las posibilidades de crecimiento y de desarrollo de la economía. La caída de los precios del petróleo hizo que México enfrente dificultades de pago de su deuda externa a principios de los ochenta, y que la deuda per se se convirtiera en un obstáculo para el crecimiento de la economía.

3.-México también utilizó el petróleo como un instrumento de política exterior orientado a abrir espacios en la política internacional para promover los intereses políticos y económicos del país. México buscó desarrollar un liderazgo internacional con una política exterior independiente y buscó siempre preservar dicha independencia. Por ello, evitó integrarse a la OPEP y a cualquier otro organismo, tratado o arreglo regional o internacional que restringiera su capacidad de maniobra, entre ellos, el GATT hasta 1986 o NAFTA en 1994.

4.- La profundización de la crisis económica y la cada vez mayor dependencia económica de México del mercado estadounidense, ha forzado a 
los gobiernos mexicanos desde 1983 ha realizar ajustes económicos mediante los que se ha buscado liberalizar el mercado y volcar el rumbo de su modelo de desarrollo hacia el comercio exterior. Ello ha implicado la integración del país al GATT y al NAFTA. La redefinición del modelo de desarrollo ha reducido el grado de independencia de la política exterior de México frente a los Estados Unidos. Como resultado, México bajó, desde la administración de Salinas de Gortari, el perfil de su diplomacia en Centroamérica promoviendo un nuevo enfoque que no es confrontacional con los intereses estadounidenses y que, además, es compatible con sus intereses económicos y comerciales. Es decir, ha habido una mutación desde la alta política hacia la baja política, donde los aspectos económicos y comerciales se sobreponen a los de naturaleza eminentemente políticos y militares relacionados con la búsqueda de poder y de prestigio en las relaciones internacionales. El poder y el prestigio ahora se asocian, cada vez más, con la obtención de una mayor riqueza económica y de una mayor competitividad en el comercio internacional. La política exterior de México, en consecuencia, tiende a concentrarse cada vez más, en aspectos relacionados con la baja política tales como comercio internacional e integración económica a nivel regional.

Adicionalmente, conforme la caída de los precios del petróleo se agudizó en la década de 1980, México abandonó su política de distanciamiento de la OPEP por otra de estrecha cooperación, aunque aún sin asumir membresia de dicho cartel. Sin embargo, al decir de un analista sobre la materia, México llegó a ser, paradójicamente, el miembro más disciplinado de este organismo.

La crisis económica y política de 1994-95, demuestra que el petróleo sigue siendo importante para la política industrial y comercial de México y que éste sigue siendo la base para la negociación de nuevos créditos y para la reestructuración de la deuda externa. El petróleo ha sido un arma psicológica que ha disuadido a la banca internacional a imponer fuertes sanciones financieras a México y la ha inducido a cooperar en la solución de las dificultades que en varias ocasiones ha enfrentado el país.

Durante los noventa, sin embargo, debido a la crisis económica y a la mayor dependencia de México frente a los Estados Unidos y otros países industrializados, México se ha visto forzado a abrir gradualmente su industria petrolera, sobre todo los servicios asociados con la distribución y almacenaje de gas natural, construcción de gasoductos, dándosele así una 
amplia cobertura a la inversión privada en el sector petrolero, pero manteniendo la producción bajo el monopolio estatal.

5.- Por otro lado, la década de los 90 s muestra los efectos de la existencia de una disfuncionalidad política en el proceso de ajuste de la economía mexicana. Dicha disfuncionalidad está dada por la falta de un paralelismo entre la reforma económica y la necesidad de emprender una reforma política que lleve a la sociedad y política mexicana hacia una mayor apertura democrática que supere la actual nomenclatura priista y que además garantice la paz al interior del país. Esta disfuncionalidad política ha condicionado el éxito del ajuste económico y ha llevado a la sociedad y política mexicana a niveles inusitados de violencia, especialmente en 1995 y 1995. Sin embargo, el triunfo electoral de Cuauhtemoc Cárdenas en las elecciones para elegir Gobernador para la ciudad de México en julio de 1997, podría ser un indicación de que Méjico se orienta cada vez más hacia la construcción democrática.

6.- Las crisis que durante la presente década han golpeado a México requieren para su solución de una visión integral del proceso de reforma. Por un lado, se hace necesaria una ponderación en el ajuste económico con el fin de potenciar más el factor humano y a la vez propiciar el crecimiento de la economía basado más en el ahorro interno y en la eficiencia económica, y menos en las disposiciones del capital o inversión extranjera. La dependencia del país del capital extranjero (ante el cual ha ido perdiendo capacidad regulatoria justamente debido a la aplicación del ajuste estructural en el área financiera, como lo demostró la crisis de 1995) es altamente peligrosa y debería ponderarse. Por otro lado, la visión integral del proceso de reforma económica requiere enfrentar el desajuste político mediante la reforma del aparato político a efecto de que la política nacional se vuelva más competitiva entre los diferentes partidos políticos, con normas claras y justas, de manera que la reforma política también contribuya al desarrollo nacional, un desarrollo que combine el crecimiento económico con la justicia social. 
Bibliografia:

Rafael A. Sánchez

El Impacto de la Industria

Petrolera en la Economía

Mexicana.

Adelman, MI.A. (1984)

The Multinationals in the World Oil Market:

the 1970s and 1980s

In: KINDLEBERGER, C.P and

AUDRETSCH, D.B (eds) 1984, The

Multinational Corporation in the 1980s,

Cambridge, U.S.A, London, England

THE MIT PRESS 2nd Ed, 122-135 PP.

Alvarez Bejar, A. Etal (1993)

México 1988-1991: A Successful Economic

Adjustment Program?

Latin American Perspectives Vol.20 N.3,

Issue 78, London, Summer 1993, 32-45 PP.

Basurto, J. (1976) El Conflicto International en torno al Petroleo Mexicano, México, SIGLO XXI Editores s.a., 1st Ed., 138 P.

Bennett, D et al (1978)

Mexico and Multinational Corporations:

An Explanation of State Action,

In: GRUNWALD, J (ed) Latin America and

World Economy: A Changing International

Order, USA, SAGE PUBLICATIONS,

Vol.2, 1.Ed, PP.257-282.

Bermudez, A.J. (1976) La Politica Petrolera Mexicana, México, JOAQUIN MORTIZ

S.A., 1st Ed. 122 P.

Bromley, S (1991) American Hegemony and World Oil: The Industry, The State System and the World Economy, England, POLITY PRESS, 1.Ed, 316 P.

Brown, J.C. (1985) Jersey Standard and the Politics of Latin American Oil Production, 1911-1930, In: WIRTH, J.D (ed) 1985, Latin American Oil Companies and the Politics of Energy, US, University of Nebraska Press, 1st Ed, 1-50 PP.
Canning House (1998) México \& the European Union: Investment \& Business Prospects, México City, 28 May 1998, 25 P.

Calvert, P (1994) The International Politics of Latin America, England, MANCHESTER UNIVERSITY PRESS, 1.Ed, 261 P.

Colby, S. S (1991)

México and the United States: A New Convergence of Interests, en: ROETT, R (ed) 1991, Mexico's External Relations in the 1990s, USA, LYNNE RIENNER PUBLISHERS, INC, 1. Ed, PP. 229-242.

Coredor Esnaola, J. (1981) El Significado Económico del Petróleo en México, Comercio Exterior, Vol. 31, No. 11, 1311-1323 PP.

Cueva, A (1985) El Desarrollo del Capitalismo en América Latina, México, SIGLO XXI, 9.Ed, 238 P.

Duran, E (1985) Pemex: The Trajectory of a National Oil Policy, in: WIRTH, J.D (ed) 1985, Latin American Oil Companies and the Politics of Energy, US, University of

Nebraska Press, 1st Ed, 145-188 PP.

Economic Review: Oil in Latin America and the Caribbean, 1971-1974, Vol.1-4.

Eisenhower, M (1962) La Alianza para el Progreso: Sus Raíces Históricas, en: DREIER, J. C (ed) 1962, La Alianza para el Progreso: Problemas y Perspectivas, México, Editorial Novaro - México, S.A. 1.Ed, PP.33-58.

Eschbach, C.L (1991) Mexico's Relations with Central America: Changing Priorities, Persisting Interest, in: ROETT, R (ed) 1991, Mexico External Relations in the 1990s, USA, LYNNE RIENNER PUBLISHERS, INC, 1.Ed, PP.171-193.

Gentleman, J. (1984) Mexican Oil and Dependent Development, New York, PETER LANG PUBLISHING, 1st Ed. 260 P. 
Grayson, G.W. (1989) Oil and Latin

American Politics, in: Latin American Research Review, Vol. XXIV, No.3, 1989 201-211 PP.

Grayson, G.W (1988) Oil and Mexican Foreign Policy, USA, UNIVERSITY OF PITTSBURH, 1.Ed, 207 P.

Grugel, J (1996) Latin America and the Rethinking of the Americas, in: GAMBLE, A \& PAYNE, A (eds) 1996, Regionalism \& World Order, England, MACMILLAN PRESS, 1.Ed, PP.131-167.

Harris, N. (1993) Mexican Trade and Mexico-U.S. Economic Relations In: HARVEL, $N$ (Ed) 1993, Mexico: Dilemmas of Transition, London, THE INSTITUTE OF LATIN AMERICAN STUDIES AND BRITISH ACADEMIC PRESS, 1st Ed. PP.151-171.

Herzog F, J.S (1991) México and the World: Opportunities and Risks in the 1990s: en, ROETT, R (ed) 1991, Mexico's External Relations in the 1990s, USA, LYNNE RIENNER PUBLISHERS, ICN, 1. Ed, PP. 23-35.

Hurrell, A (1995) Regionalism in the Americas, in: FAWCETT, L \& HURRELL, A (eds) 1995, Regionalism in World Politics, England, OXFORD UNIVERSITY PRESS, 1.Ed, PP.250-282.

Jenkins, R (1991) Trasnational Corporations and Uneven Development, London and New York, Routledge, 2nd Ed, $229 \mathrm{P}$.

Jenkins, R (1987) Transnational Corporations and the Latin American Automobile Industry, London, MACMILLAN PRESS, 1.Ed, 170 P.

Latin American Weekly Reports, from 1 January 1982 to 19 November 1987.
Lustig, N (1997) Los Estados Unidos al rescate: La Asistencia Financiera a México en 1982 y 1995, en: Revista de la CEPAL, No.61, PP.39-61.

Miron, R. M, \& Perez, G (1988)

Lopez Portillo: Auge y Crisis de un Sexenio, Mexico, PLAZA \& VALDEZ, 1st, Ed, 196 P.

Philip, G (1982)

Oil and Politics in Latin America, L.ondon, Cambridge University, 1st Ed, 577 P.

Pinelo, A. J (1973) The Multinational Corporation as a force in Latin American Politics: A case of Study of the International Petroleum Company in Peru, London, PRAEGER PUBLISHERS, 1.Ed, $171 \mathrm{P}$.

Platt's Weekly Analysis of World Oil and Gas, Vol. 6, N.21, MCGRAW-HILLL PUBLICATION, May 24,1992,12 p.

Randall, L (1989)

The Political Economy of Mexican Oil, New York, PRAEGER, 1st Ed, 228 P.

Ranson, D (1994) Mexico: Through the Tortilla Curtain, The New Internationalist, England, January 1994, PP.4-29.

Roett, R (ed) 1991, Mexico's External Relations in the 1990s US, LYNNE RIENNER PUBLISHERS, INC, 1. Ed, 279 P.

Rojas, R (1991)

Mexico: Five Years of Debt Crisis, en: ALTVATER, E et al (eds) 1991, The Poverty of Nations: A Guide to the Debt Crisis from Argentina to Zaire, England, ZED BOOKS Ltd, 1. Ed, PP.168-181.

Rojas, T. D (1995)

Mexico's Dysfunctional Neoliberalism, en: North-South Focus, Vol. IV, N.1, 1995 , UNIVERSITY OF MIAMI, PP.1-8. 
Rollins, C. E (1970)

Mineral Development and Economic

Growth, in: RODES, R. I (ed) 1970 ,

Imperialism and underdevelopment: $\mathrm{A}$

Reader, New York \& London, 7th E.d, 181-204 PP.

Ros, J (1995) Reflexiones sobre la Crisis de México y sus implicaciones de política macroeconómica, en: América Latinal Internacional Vol.2. N.1, Argentina, FLACSO, Otoño-Invierno, PP.136-144.

Roxborough, I (1988)

Theories of Underdevelopment, London, MACMIILAN EDUCATION LTD, 9.Ed, $175 \mathrm{P}$.

Saxe-Fernandez, J (1993)

La otra cara del T.L.C, en: SANCHEZ, O.M Y DELGADO, J (compiladores) 1993, Una Contribución al debate Integración regional, San José, Costa Rica, FLACSO-UNA, 1.Ed, PP.199-218.

Tanzer, M (1970) The Political Economy of International Oil and the Underdeveloped Countries, London, TEMPLE SMITH, 1st Ed, 435 P.

Terzian, P (1985) OPEC: The Inside Story, Great Britain, ZED BOOKS LTD, 355 P.

The Economist,

November 18th-24th 1995, P. 124.

The Economist, May 4th-10th 1996, PP.97-98.

The Economist, June 1st - 7th 1996, PP.73-74.

The Economist, June 29th-July 5th 1996, PP.19,95-96. The Economist, July 13th, 1996, P.6.

The Economist, July 18th,1997, PP.53-54.

The Financial Times Survey on Latin American Finance, London, Monday April 11, 1994, PP. I-VIII.
Tugendhat, C (1968) Oil The Biggest

Business, Great Britain, EYRE \&

SPOTTISWOODE, 1st Ed, $318 \mathrm{P}$.

Turner, L (1978) Oil Companies in the International System, England, BILLING \& SONS LIMITED, 1.Ed, 240 P.

Villareal, R (1981) El Petróleo como Instrumento de Desarrollo y de Negociación Internacional: México en los Ochentas, En: El Trimestre Económico, Vol. XLVIII (1), No.189, PP.3-44.

Villegas, A (1986) Reformismo y Revolución en el pensamiento latinoamericano,

México, SIGLO XXI, 6.Ed, 359 P.

Wirth, J D (ed) (1985) Latin American Oil Companies and the Politics of Energy, US, University of Nebraska Press, 1st Ed, 281 P.

Bachillerato en Relaciones

Internacionales, (1990)

Universidad Nacional de Costa Rica.

Licenciatura en Relaciones

Económicas Internacionales, (1992)

Universidad Nacional de Costa Rica.

Maestria en: Politics of International

Resources and Development, (1994)

Universidad de Leeds, Inglaterra. 